\title{
Actions of bevacizumab and ranibizumab on microvascular retinal endothelial cells: similarities and differences
}

\author{
Heidrun L Deissler, ${ }^{1}$ Helmut Deissler, ${ }^{2}$ Gabriele E Lang ${ }^{1}$
}

${ }^{1}$ Department of Ophthalmology, University of Ulm, Ulm, Germany ${ }^{2}$ Department of Obstetrics and Gynaecology, University of Ulm, Ulm, Germany

\section{Correspondence to}

Dr Heidrun L Deissler, Department of Ophthalmology, University of Ulm Prittwitzstrasse 43, D-89075 Ulm, Germany; heidrun. deissler@uniklinik-ulm.de

Accepted 5 April 2012 Published Online First 26 April 2012

\section{(2) UNLCKI:}

This paper is freely available online under the BMJ Journals unlocked scheme, see http:// bjo.bmi.com/site/about/ unlocked.xhtml

\section{ABSTRACT}

Background Retinal endothelial cells are crucially involved in the genesis of diabetic retinopathy which is treated with vascular endothelial growth factor (VEGF) inhibitors. Of these, ranibizumab can completely restore VEGF-induced effects on immortalised bovine retinal endothelial cells (iBREC). In most experiments supporting diabetic retinopathy therapy with bevacizumab, only nonretinal EC or retinal pigment epithelial cells have been used. Also, bevacizumab but not ranibizumab can accumulate in retinal pigment epithelial cells.

Objective To investigate the effects of bevacizumab on VEGF-induced changes of iBREC properties and potential uptake and accumulation of both inhibitors.

Methods Uptake of VEGF inhibitors by iBREC with or without pretreatment with $\mathrm{VEGF}_{165}$ was visualised by immunofluorescence staining and western blot analyses. Measured transendothelial resistance (TER) of iBREC $\left( \pm \mathrm{VEGF}_{165}\right)$ showed effects on permeability, indicated also by the western blot-determined tight junction protein claudin-1. The influence of bevacizumab on proliferation and migration of iBREC was studied in the presence and absence of $\mathrm{VEGF}_{165}$.

Results Bevacizumab strongly inhibited VEGF-stimulated and basal migration, but was less efficient than ranibizumab in inhibiting VEGF-induced proliferation or restoring the VEGF-induced decrease of TER and claudin1. This ability was completely lost after storage of bevacizumab for 4 weeks at $4^{\circ} \mathrm{C}$. Ranibizumab and bevacizumab were detectable in whole cell extracts after treatment for at least $1 \mathrm{~h}$; bevacizumab accumulated during prolonged treatment. Ranibizumab was found in the membrane/organelle fraction, whereas bevacizumab was associated with the cytoskeleton.

Conclusion Both inhibitors had similar effects on retinal endothelial cells; however, some differences were recognised. Although barrier properties were not affected by internalised bevacizumab in vitro, potential adverse effects due to accumulation after repetitive intravitreal injections remain to be investigated.

\section{INTRODUCTION}

Vascular endothelial growth factor (VEGF) and its receptors are promising targets for treating diabetic retinopathy (DR), particularly diabetic macular oedema (DME), as elevated levels of VEGF have been found in the vitreous fluid and retinal vasculature of patients. ${ }^{1-3}$ Accordingly, the VEGF-binding antibody fragment ranibizumab has recently been approved for DME therapy; the humanised VEGFspecific antibody bevacizumab is also used. ${ }^{4}$ The most important variant, VEGF 165 , not only elevates permeability of retinal endothelial cells (REC), likely leading to DME in vivo, but also stimulates proliferation and migration of REC to initiate neovascularisation. ${ }^{6-12}$ Several in vitro studies have confirmed that VEGF-stimulated proliferation of retinal or choroidal endothelial cells is inhibited by ranibizumab or bevacizumab. ${ }^{10} 12{ }^{13}$ Increased permeability of immortalised bovine REC (iBREC) induced by long-term exposure to VEGF 165 , accompanied by loss of plasma membrane-localised tight junction (TJ) protein claudin-1, was completely restored by treatment with ranibizumab, even in the presence of other growth factors. ${ }^{9}{ }^{14}$ Despite their similarity, deviating pharmacological activities of the VEGF inhibitors may result from differences in accumulation in relevant cell types, which has been shown for retinal pigment epithelial (RPE) cells: only bevacizumab was transported through the plasma membrane and its intracellular amounts increased over several days. ${ }^{15}$ Sufficiently accumulated bevacizumab affected phagocytotic uptake of photoreceptor outer segments by RPE cells and also their barrier function. ${ }^{16} 17$ In contrast, ranibizumab only transiently impaired the barrier formed by these cells, and their phagocytotic uptake was not altered by exposure to this drug. ${ }^{16} 17$ These findings suggest that mechanisms of therapeutic activity of both VEGF inhibitors involving REC might also differ in relevant details. Therefore we used the established model cell line iBREC to investigate the efficiency of bevacizumab to restore VEGF-induced effects on proliferation, migration and barrier function. In addition, uptake of both VEGF inhibitors by iBREC and potential consequences were studied.

\section{MATERIALS AND METHODS}

\section{Reagents, antibodies and media}

Recombinant human VEGF 165 was obtained from R\&D Systems (Wiesbaden, Germany). Ranibizumab (Lucentis, $10 \mathrm{mg} / \mathrm{ml}$ ), the Fab fragment of a humanised VEGF-binding antibody, was a gift from Novartis Pharma (Nuremberg, Germany). ${ }^{18}$ The anti-VEGF antibody bevacizumab (Avastin, $25 \mathrm{mg} / \mathrm{ml}$ ) was purchased from Roche Pharma (Basel, Switzerland); aliquot parts were stored in inert plastic vessels at $4^{\circ} \mathrm{C} .{ }^{19}$ Alternatively, bevacizumab was repackaged at the pharmacy of the University Hospital Ulm and provided in syringes which were stored at $4^{\circ} \mathrm{C}$. Rabbit polyclonal antibodies binding to human claudin-1 (JAY.8) or claudin-5 (Z43.JK) and AlexaFluor 594-conjugated detection antibodies were from Invitrogen (Karlsruhe, Germany); goat polyclonal antibodies directed against canine VEGF (cross-reacting with bovine VEGF) were from R\&D Systems. 


\section{Cultivation of iBREC and treatment with growth factors and inhibitors}

Telomerase-immortalised microvascular endothelial cells from bovine retina (iBREC) were cultivated in endothelial cell growth medium (ECGM; Promocell, Heidelberg, Germany) supplemented with $0.4 \%$ endothelial cells growth supplement $/ \mathrm{H}$, $10 \mathrm{ng} / \mathrm{ml}$ epidermal growth factor and $103 \mathrm{nM}$ hydrocortisone and $5 \%$ fetal calf serum (FCS) as described previously. ${ }^{14} 20$

Prior to experiments with confluent iBREC, the serum concentration of ECGM was reduced to $0.25 \%$ FCS for $24 \mathrm{~h}$. After treatment with $100 \mathrm{ng} / \mathrm{ml} \mathrm{VEGF}_{165}$ for 2 days, cells were incubated with medium containing $100 \mathrm{ng} / \mathrm{ml} \mathrm{VEGF}$ VE, $_{165}$ and $100 \mu \mathrm{g} / \mathrm{ml} \mathrm{ranibizumab}$ or $250 \mu \mathrm{g} / \mathrm{ml}$ bevacizumab, for at least $24 \mathrm{~h}$ before cell extracts were prepared. ${ }^{14}$ To study the effect of VEGF inhibitors on unstimulated cells, iBREC were kept in medium with $100 \mu \mathrm{g} / \mathrm{ml}$ ranibizumab or $250 \mu \mathrm{g} / \mathrm{ml}$ bevacizumab for periods from 30 min to 6 days.

\section{Preparation of subcellular fractions and western blot analyses}

Subcellular fractions were prepared with the ProteoExtract Subcellular Proteome Extraction Kit (Merck, Darmstadt, Germany) according to the manufacturer's instructions, yielding proteins localised in the cytosol, in membranes/organelles, in the nucleus, and in components of the cytoskeleton. Cytosolic, membrane and nuclear fractions were cleared by additional centrifugation $\left(10000 \times \mathrm{g}, 4^{\circ} \mathrm{C}\right)$ for $10 \mathrm{~min}$.

Western blot analyses of whole cell extracts or subcellular fractions were performed as described. ${ }^{11}{ }^{14}$ Analyses of ranibizumab and bevacizumab were based on immunoreactivity of polyclonal antibodies (coupled to horseradish peroxidise) with human IgG (1:20000, Invitrogen). For semi-quantitative assessment, specific chemiluminescence signals were compared to those of standard samples used in the range $0.5-50 \mathrm{ng}$.

\section{Immunofluorescence staining}

Confluent monolayers of iBREC on fibronectin-coated twochamber slides (Nunc, Wiesbaden, Germany) were treated with effectors as described above and antigens were visualised by immunofluorescence staining. ${ }^{10}$ Internalised ranibizumab or bevacizumab were stained by incubation with AlexaFluor594coupled polyclonal antibodies (1:10000) against human IgG for 90 min after blocking with 10\% FCS/PBS for 30 min. To determine the limit of detection, diluted samples of the inhibitors were spotted on an appropriate membrane and processed alike.

\section{Transendothelial electrical resistance of cell layers}

To assess paracellular permeability of iBREC, transendothelial electrical resistance (TER) was measured as described previously. ${ }^{11} 14$ Normalised TER values were calculated in relation to the TER measured in low serum medium immediately before the medium was replaced by fresh medium containing effectors.

\section{Cell migration and proliferation assays}

Cell migration assays were performed in a modified Boyden chamber; enzymatic conversion of WST-1 (Roche), indicative of proliferating cells, was measured $24 \mathrm{~h}$ after addition of effectors to iBREC as described previously. ${ }^{10}$ Values were normalised to those obtained with control cells not treated with effectors.

\section{General considerations and statistical analyses}

In all experiments, control cells were processed identically in medium only lacking the effector(s) under investigation. All experiments were repeated at least three times; in each experiment, data were generated from multiple replicates. The
Mann-Whitney $U$ test was used to compare sets of experimental data; differences resulting in $p$ values below 0.05 were considered significant. Results are presented either as conventional box-whiskers diagrams showing means and percentiles $(75 \%, 25 \%)$ or by providing means and corresponding standard deviations.

\section{RESULTS \\ Bevacizumab inhibits VEGF $_{165}$-induced proliferation and migration}

Our previous studies showed that stimulation of proliferation and migration of iBREC with $\mathrm{VEGF}_{165}$ is completely suppressed by $100 \mu \mathrm{g} / \mathrm{ml}$ ranibizumab. ${ }^{10}$ To compare the inhibitory effect of the related drug bevacizumab, serum-starved iBREC were exposed to VEGF 165 and bevacizumab for $24 \mathrm{~h}$ before conversion of WST-1 was determined as a measure of cell proliferation. Only partial inhibition of VEGF-stimulated proliferation by bevacizumab was observed under these conditions (figure 1A). VEGF-stimulated migration of iBREC towards fibronectin in a modified Boyden chamber was not only strongly inhibited by bevacizumab, but was even driven below basal migration rates (figure 1B). The effect of bevacizumab on proliferation or migration of iBREC was not dependent on time and conditions of its storage prior to the experiments.

\section{Bevacizumab restores a VEGF $_{165}$-impaired iBREC barrier}

In accordance with previous investigations, treatment of iBREC with VEGF $_{165}$ significantly decreased the TER within 2 days (figure 2A). ${ }^{14}$ After addition of bevacizumab to the VEGFpretreated cells, TER increased within 1 day but reached normal values only during prolonged exposure (figure 2A), whereas almost complete reversion was achieved after 1 day with ranibizumab. Like ranibizumab, bevacizumab completely reinstated the VEGF-induced loss of claudin-1 (figure 2B,C). This effect of potential therapeutic relevance on TJs was entirely lost after
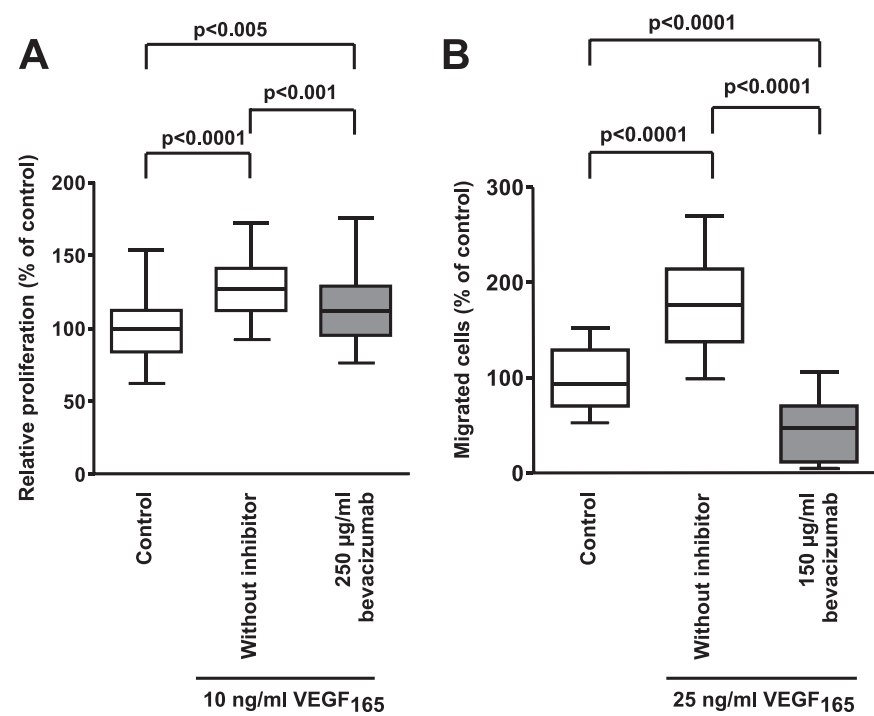

Figure 1 Vascular endothelial growth factor $\left(\mathrm{VEGF}_{165}\right)$-stimulated proliferation and migration of immortalised bovine retinal endothelial cells (BREC) is inhibited by bevacizumab. (A) Serum-starved iBREC were incubated with VEGF $_{165}$ in the presence or absence of bevacizumab and their proliferation was measured after $24 \mathrm{~h}$. (B) iBREC migration towards fibronectin was measured in a modified Boydenchamber. VEGF 165 -stimulated migration was inhibited by bevacizumab below the level of basal migration. 
A

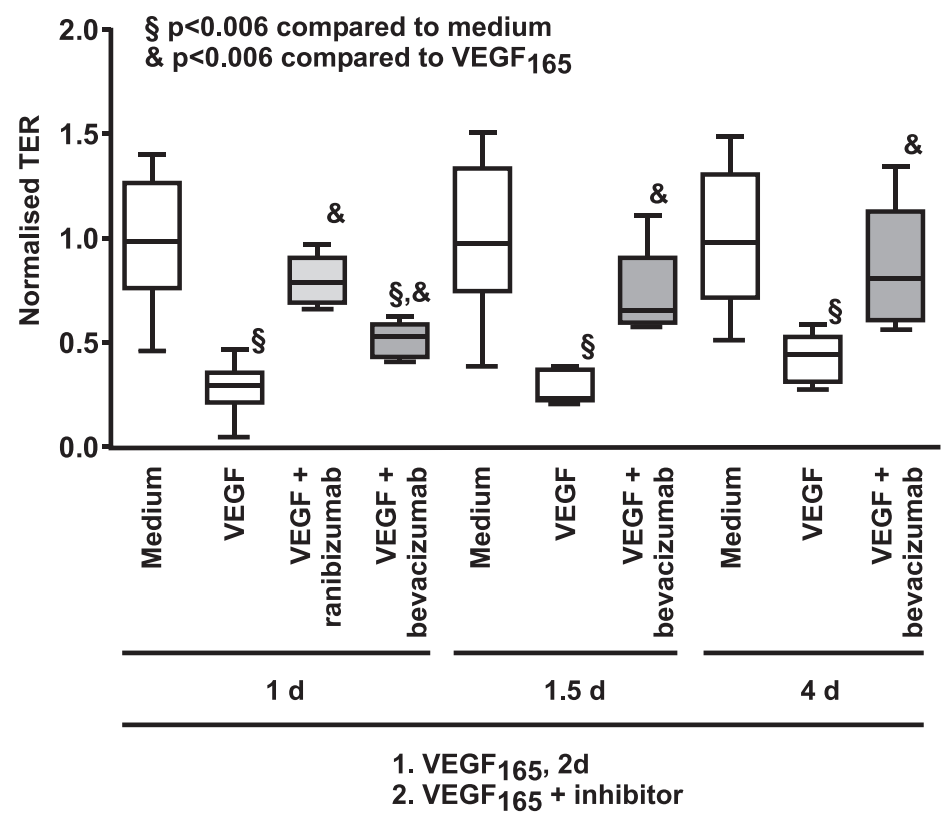

B

1. 2 d VEGF

2. 1 d VEGF + bevacizumab

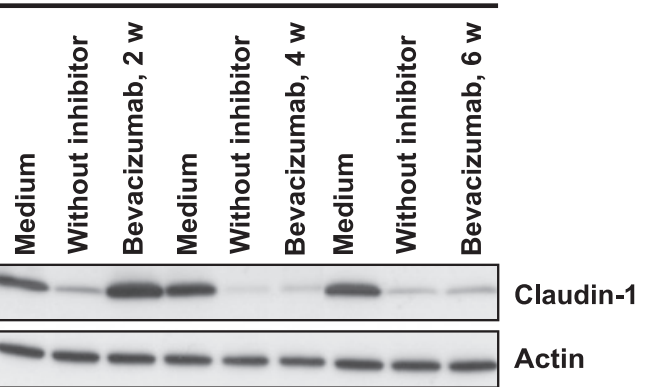

C

1. $2 \mathrm{~d}$ VEGF

2. 1 d VEGF + ranibizumab

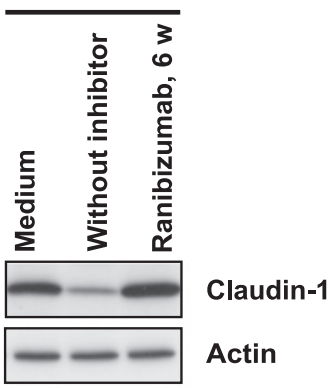

Figure 2 Vascular endothelial growth factor $\left(\mathrm{VEGF}_{165}\right)$-induced decrease of transendothelial resistance (TER) and claudin-1 expression are restored by bevacizumab. Confluent immortalised bovine retinal endothelial cells (BBREC) were treated with $100 \mathrm{ng} / \mathrm{ml} \mathrm{VEGF}_{165}$ for 2 days, before $250 \mu \mathrm{g} / \mathrm{ml}$ bevacizumab or $100 \mu \mathrm{g} / \mathrm{ml}$ ranibizumab were added. (A) TER was measured at indicated time points after start of incubation with $\mathrm{VEGF}_{165}$ and inhibitor. Complete reversion of TER-decrease was achieved after treatment with bevacizumab for 1.5 days or with ranibizumab for 1 day. (B) iBREC pretreated with $\mathrm{VEGF}_{165}$ were exposed to bevacizumab which had been stored for 2, 4 or 6 weeks at $4^{\circ} \mathrm{C}$ and expression of claudin-1 was analysed by western blot $24 \mathrm{~h}$ later. The ability of bevacizumab to restore lost claudin-1 vanished during prolonged storage at $4^{\circ} \mathrm{C}$. (C) iBREC were treated as described in (B) but ranibizumab stored at $4^{\circ} \mathrm{C}$ for 6 weeks was used to restore claudin-1 completely. (D) iBREC were pretreated for $2 \mathrm{~h}$ with $100 \mu \mathrm{g} / \mathrm{ml}$ ranibizumab or $250 \mu \mathrm{g} / \mathrm{ml}$ bevacizumab (stored at $4^{\circ} \mathrm{C}$ for 8 weeks) before $100 \mathrm{ng} / \mathrm{ml} \mathrm{VEGF}_{165}$ was added for $24 \mathrm{~h}$. Both inhibitors prevented VEGFinduced loss of claudin-1.

storage of the repackaged solutions of bevacizumab at $4^{\circ} \mathrm{C}$ for more than 4 weeks (figure $2 B$ ). In contrast, ranibizumab effectively reverted the loss of claudin-1 when stored under the same conditions (figure 2C). Whereas the capacity of bevacizumab to revert VEGF-induced vanishing of claudin-1 was dependent on its storage history, prevention of this process was not affected, even after prolonged storage (figure 2D). Western blot analyses confirmed that neither protein fragmentation nor formation of aggregates occurred during long-term storage of bevacizumab or ranibizumab solutions.

\section{Uptake of bevacizumab and ranibizumab by iBREC}

First we confirmed that the Fab fragment ranibizumab and the whole antibody bevacizumab were both bound by polyclonal antibodies against human IgG, and that the detection limits (25 ng for immunofluorescence staining, $0.5 \mathrm{ng}$ for western blot analyses) were low enough. To monitor uptake by iBREC, their confluent monolayers were incubated with bevacizumab or ranibizumab for various periods from several hours to 6 days. Internalised drugs were visualised by immunofluorescence staining or determined in cell lysates (figures 3 and 4). After treatment for $30 \mathrm{~min}$, a diffuse bevacizumab-specific staining was observed, which was focused around the nucleus in cells that had been exposed longer to this antibody (figure 3, right column). Staining intensity and pattern were not affected by pretreatment with $\mathrm{VEGF}_{165}$ for 1 day. In contrast to the observed uptake of bevacizumab, considerable amounts of ranibizumab were not detected by immunofluorescence staining in iBREC treated with this antibody fragment (figure 3, middle column). These results were confirmed by western blot analyses of whole cell extracts of iBREC treated with the VEGF inhibitors: bevacizumab was detectable after $1 \mathrm{~h}$ and accumulated during further incubation until day 6 (figure 4A). In contrast, less ranibizumab was taken up slower by iBREC and, despite prolonged incubation with the antibody fragment, the amount of internalised ranibizumab remained constant (figure 4B). Most of the bevacizumab absorbed by iBREC was found associated with the cytoskeleton and a smaller part in the subcellular fraction consisting of membranes and organelles (figures 3 and $4 \mathrm{C})$, whereas ranibizumab was present in the membrane/ organelle fraction but did not co-occur with cytoskeleton proteins (figure 4D). The different subcellular localisations of ranibizumab and bevacizumab were not affected by extended exposure or pretreatment with VEGF ${ }_{165}$. In these experiments, VEGF was mainly detected in the membrane/organelle fraction in the absence or presence of VEGF inhibitors.

\section{Effects of bevacizumab and ranibizumab on barrier, migration and proliferation of unstimulated iBREC}

Destabilisation of the cell barrier, as reported for bevacizumabtreated RPE cells, was not observed when TER of iBREC was monitored during incubation with ranibizumab or bevacizumab for up to 6 days (figure $5 \mathrm{~A}$ ). ${ }^{17}$ Constant localisation of the tightjunction proteins claudin- 1 and claudin- 5 in the plasma 

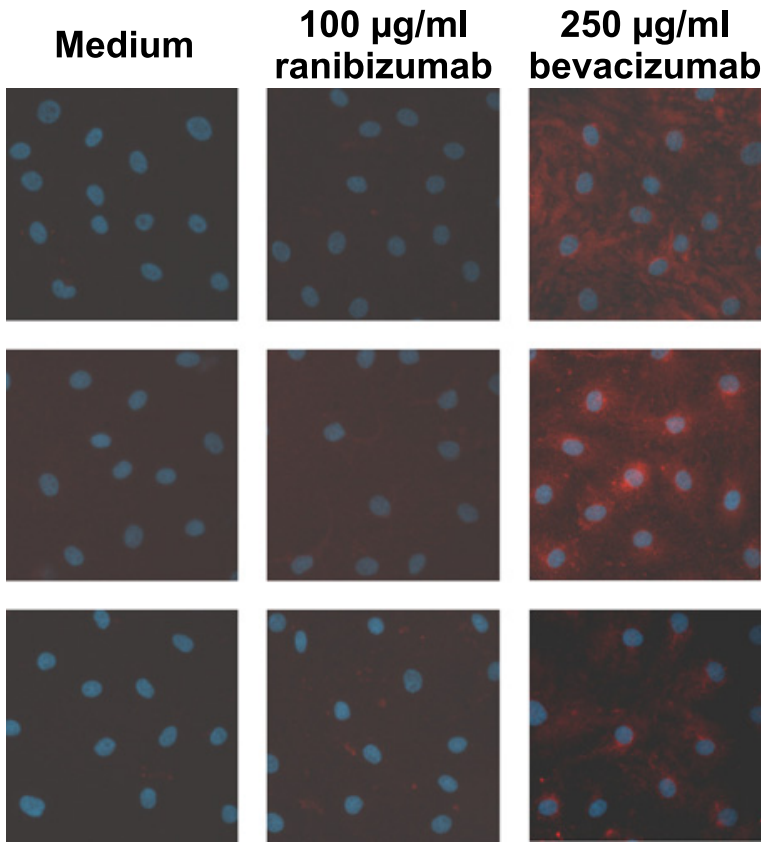

$0.5 \mathrm{~h}$

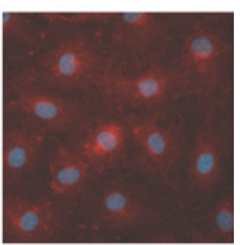

$6 \mathrm{~h}$

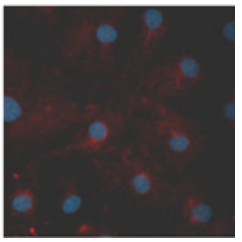

Figure 3 Visualisation of bevacizumab internalised by immortalised bovine retinal endothelial cells (BREC). iBREC were treated with bevacizumab (right column) or ranibizumab. After indicated times of incubation, inhibitors were visualised by immunofluorescence staining with antibodies against human IgG. Staining of ranibizumab-treated cells (middle column) was similar to the faint unspecific signals observed in control cells kept in standard medium (left column). Incubation with bevacizumab resulted in strong intracellular staining of BREC.

membrane was also indicative of a strong and stable barrier (figure $5 \mathrm{~B}, \mathrm{C}$ ).

Migration of iBREC towards fibronectin was not altered in the presence of $60 \mu \mathrm{g} / \mathrm{ml}$ ranibizumab as shown by normalised migration rates of $104 \% \pm 34 \%$ versus $100 \% \pm 31 \%$ (control). In contrast, $150 \mu \mathrm{g} / \mathrm{ml}$ bevacizumab strongly and significantly reduced basal migration rates of iBREC (normalised values of $43 \% \pm 27 \%, p<0.0001$ for comparisons with control and ranibizumab-treated cells), indicating VEGF-independent effects of bevacizumab. Basal proliferation of iBREC (normalised rates of $100 \% \pm 12 \%$ ) was not significantly affected by ranibizumab $(104 \% \pm 12 \%)$ or bevacizumab $(94 \% \pm 18 \%)$.

\section{DISCUSSION}

The humanised VEGF-binding antibody bevacizumab is widely used off-label to treat DME. ${ }^{5}$ Although REC are considered the most important target cells of VEGF in the development and progression of this disease, in vitro experiments performed to understand the mechanisms of the therapeutic effects of bevacizumab have been focused almost exclusively on non-retinal EC or RPE cells. ${ }^{13} 151621$ In this investigation we used iBREC, a retinal cell line with the distinct advantage over primary ECs that contaminating cells of other types cannot be present in the cultures. $^{20}$ Studies with iBREC ideally complement investigations based on rodent models of diabetes and may even be more relevant to clinical applications of drugs under investigation, because of the higher similarity of bovine proteins to their human counterparts. In our previous studies based on the iBREC model, we showed that ranibizumab, in addition to efficient inhibition of VEGF-stimulated proliferation and migration, can completely restore the VEGF-induced impairment of the endothelial barrier; this provided a rationale for using this antibody
A

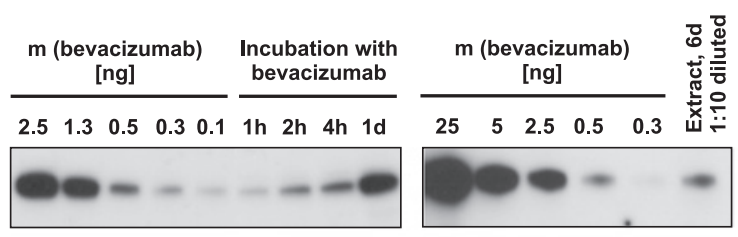

B

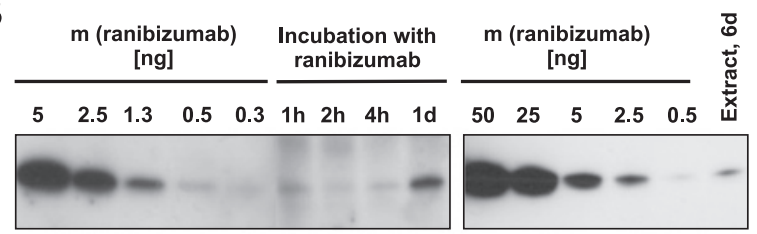

C

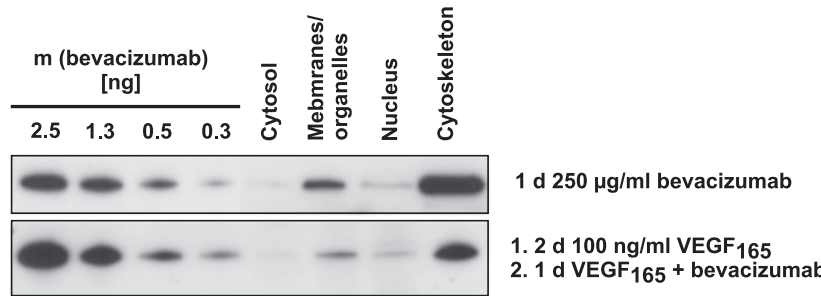

D

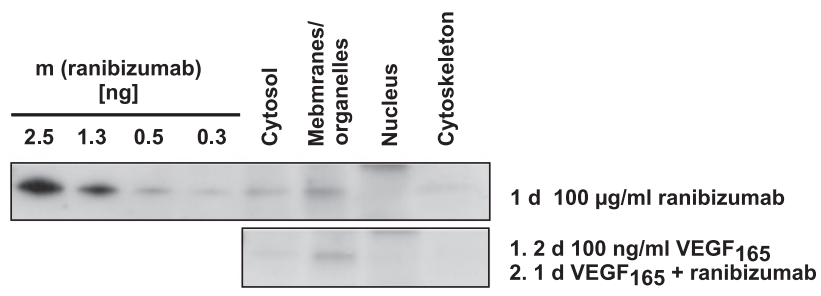

Figure 4 Semi-quantitative assessment of bevacizumab and ranibizumab in subcellular fractions of immortalised bovine retinal endothelial cells (iBREC). (A,B) iBREC were treated for $1 \mathrm{~h}$ to 6 days with $250 \mu \mathrm{g} / \mathrm{ml}$ bevacizumab $(A)$ or $100 \mu \mathrm{g} / \mathrm{ml}$ ranibizumab $(B)$ and whole cell extracts of $10^{5}$ cells $(A)$ or $3 \times 10^{5}$ cells $(B)$ were subjected to western blot analyses. Defined amounts of both inhibitors were loaded for semiquantitative assessment. The band specific for ranibizumab was most intense after treatment for 1 day. During prolonged exposure, the intracellular amount of bevacizumab but not that of ranibizumab increased. $(C, D)$ iBREC were treated for 1 day with bevacizumab $(C)$ or ranibizumab (D) in the absence or presence of vascular endothelial growth factor $\left(\mathrm{VEGF}_{165}\right)$; subcellular fractions of $2 \times 10^{4}$ cells $(\mathrm{C})$ or $5 \times 10^{4}$ cells (D) were analysed. Defined amounts of both inhibitors were loaded for semi-quantitative assessment. Ranibizumab was detected in the membrane/organelle fraction. In contrast, higher amounts of bevacizumab were mainly found in the fraction of cytoskeleton proteins. Localisation was not affected by pretreatment with VEGF $_{165}$.

fragment in DME therapy. ${ }^{4} 1011{ }^{14}$ Stimulation of iBREC was carried out in these experiments, with concentrations of VEGF similar to those measured in the vitreous fluid of DR patients; concentrations of ranibizumab and bevacizumab reflected values found to be achievable by standard therapies with these drugs. ${ }^{1-5}$ We confirmed that bevacizumab inhibits VEGFinduced proliferation but is less efficient than ranibizumab; this was also observed in experiments with human REC and could be a consequence of its much lower affinity to VEGF. ${ }^{12}{ }^{18}$ Likewise, the ability of bevacizumab to re-establish an intact iBREC barrier that had been deranged by VEGF, was lower than that of ranibizumab. Despite being observed in vitro, this difference might be seen as a challenge to the assumption that both drugs are equivalent in the treatment of $\mathrm{DR}{ }^{5}$ Also of potential relevance for its clinical application is the surprising finding that bevacizumab repackaged in syringes and stored at $4^{\circ} \mathrm{C}$ for more 
A

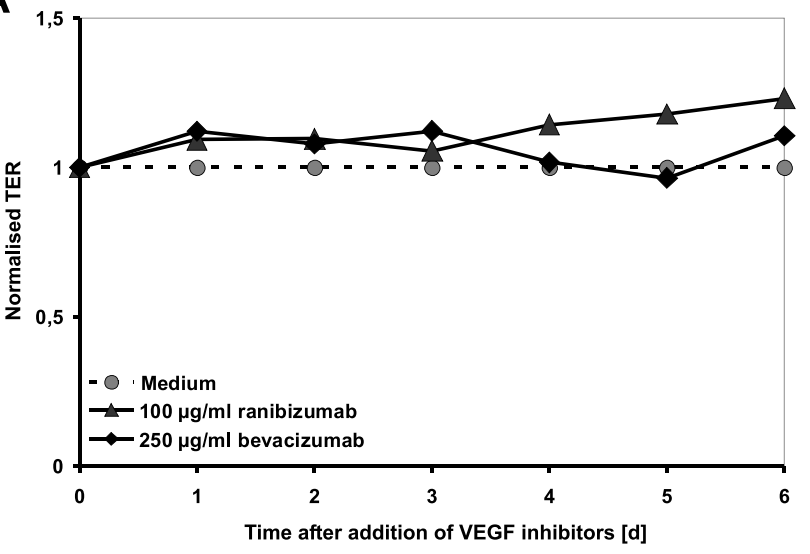

B

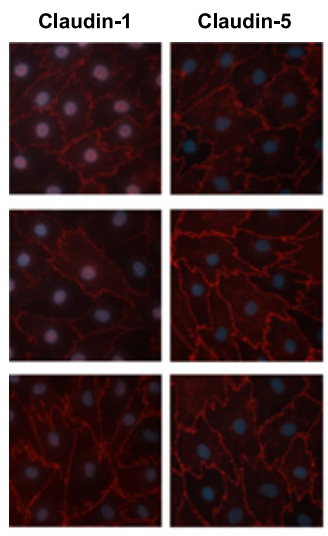

Medium

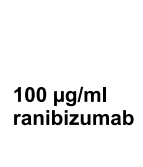

$250 \mu \mathrm{g} / \mathrm{ml}$
bevacizumab

C
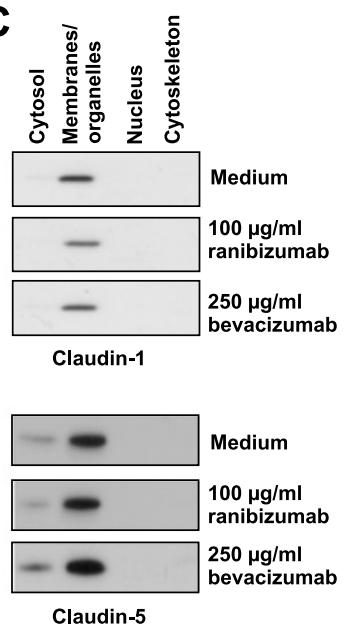

Figure 5 Transendothelial resistance (TER) and localisation of claudin-1 were not altered by bevacizumab or ranibizumab. Confluent immortalised bovine retinal endothelial cells (BBREC) were treated with bevacizumab or ranibizumab for several days. (A) Constantly high TER, indicative of a stable iBREC barrier, was measured despite the presence of vascular endothelial growth factor (VEGF) inhibitors during cultivation. (B) Unchanged expression of claudin- 1 and claudin- 5 by iBREC treated for 6 days with VEGF inhibitors was determined by immunofluorescence staining. (C) Western blot analyses of subcellular fractions of iBREC treated with VEGF inhibitors for 1 day showed stable expression and localisations of claudin- 1 and claudin-5.

than 2 weeks lost its ability to restore VEGF-induced loss of claudin-1, an indicator of an intact barrier. In one previous study, loss of bevacizumab activity was reported to be caused by freezing and thawing, after which it failed to prevent VEGFstimulated increase of permeability of choroidal EC. ${ }^{21}$ It has been suggested that partial inactivation of bevacizumab in solution might be due to formation of antibody aggregates with potentially masked binding sites, a process more frequently observed when the solutions were stored in syringes. ${ }^{22} 23$ However, in solutions of bevacizumab used in this study, such aggregates were undetectable; we assume that partial loss of activity was more likely caused by yet unidentified reactions leading to modification of the protein. In contrast to the reversion of a state established during exposure to VEGF for days, reflecting the pathophysiological conditions typical for DME, prevention of the effects of VEGF on proliferation, migration and expression of claudin-1 by bevacizumab was not dependent on the time and conditions of its storage prior to the experiments. Preventing VEGF-induced processes may simply require lower amounts of an inhibitor, and it is therefore less sensitive to partial inactivation during storage than reversion of established states. In accordance with this assumption, preventing VEGFinduced loss of claudin- 1 in iBREC was achieved with much lower concentrations of an inhibitor of VEGF receptor 2 than those for restoring VEGF-decreased claudin- $1 .{ }^{14}$ This suggests that elimination of VEGF from the extracellular space may not be sufficient to reverse its long-term effects on ECs and that additional mechanisms contribute to the therapeutic effects of drugs like ranibizumab and bevacizumab. Potential second targets may be secreted factors like VEGF or cell surface molecules on ECs, but internalised drugs may also affect intracellular processes.

After treatment for 1 day, about 40000 molecules of ranibizumab were calculated to be present inside iBREC. Association of ranibizumab with the organelle/membrane fraction is in accordance with the speculation that this substance is internalised by endocytosis to be degraded. Then the constant intracellular amounts of ranibizumab observed during prolonged exposure can be considered a steady state in which uptake and degradation of the protein are balanced. In contrast, a higher amount ( 100 000 molecules per cell) of bevacizumab measured after one day in iBREC further increased when the cells were kept in medium containing the antibody. Most of the accumulated bevacizumab was found associated with the cytoskeleton, which might be the reason for the surprisingly observed inhibition of basal migration of iBREC. Because serum-free medium was used in this assay, this inhibitory effect could not be caused by targeting residual amounts of VEGF. The part of internalised bevacizumab found in the organelle/membrane fraction could be degraded like ranibizumab, but this process seems to be not fast enough to avoid an increase of intracellular amounts. Treatment of iBREC with $\mathrm{VEGF}_{165}$ did not alter intracellular quantities or their localisation, indicating that the endocytotic uptake of ranibizumab or bevacizumab by iBREC is not dependent on binding to the antigen. This is in accordance with a different localisation of intracellular VEGF which may be taken up through other pathways. Whether binding of the constant region of the antibody bevacizumab to the Fc receptor plays a role in its internalisation, remains to be investigated.

Neither ranibizumab nor bevacizumab affected the barrier of iBREC in the absence or presence of VEGF, even when the cells were exposed to the drugs for several days. This result contrasts with those of experiments with RPE cells in which ranibizumab transiently and bevacizumab lastingly increased the permeability, showing that in the two most important cell types involved in DR and DME, barriers of cell layers and dynamics of TJs are most likely regulated in different ways. ${ }^{17}$ In an overall assessment of therapeutically relevant processes in the eye, such differences between alternative drugs and their cell type-specific effects have to be taken into consideration.

In this study we showed that the actions of ranibizumab and bevacizumab on REC were similar but differed in some respects: bevacizumab inhibited or restored VEGF-induced effects with a slightly lower efficiency than ranibizumab and accumulated in these cells. Although the barrier properties of REC were not affected by internalised bevacizumab in our in vitro experiments, adverse effects in vivo cannot be ruled out because more antibody molecules might accumulate in these cells after repetitive intravitreal injections. Transient accumulation of bevacizumab in the RPE has been observed after its intravitreal injection into the primate eye. ${ }^{24}$ This might have some functional consequences as suggested by the finding that phagocytotic uptake of photoreceptor outer segments by porcine RPE cells is inhibited after long-term exposure to bevacizumab, an 
effect not observed with ranibizumab. ${ }^{16}$ Considering the typical ages of the DME-patients and duration of treatment, these results strongly suggest further investigations to exclude any harmful long-term consequences for retinal cells due to accumulation of bevacizumab after repetitive injections.

Acknowledgements The authors thank Susanne Denning, Nadine Gubernath and Anita Ruepp for expert technical assistance.

Contributors HLD: planning of research; planning, performing (in part) and analyses of experiments; writing and revision of manuscript, approval of final version. GEL: planning of research; comments on manuscript, approval of final version. HD: writing and revision of manuscript, approval of final version.

Funding Independent research grant by Novartis Pharma GmbH, Nuremberg.

Competing interests Independent research grant by Novartis Pharma GmbH, Nuremberg.

Provenance and peer review Not commissioned; externally peer reviewed.

\section{REFERENCES}

1. Aiello LP, Avery RL, Arrigg PG, et al. Vascular endothelial growth factor in ocular fluid of patients with diabetic retinopathy and other retinal disorders. N Engl J Med 1994:331:1480-7.

2. Boulton M, Foreman D, Williams G, et al. VEGF localization in diabetic retinopathy. Br J Ophthalmol 1998:82:561-8.

3. Watanabe D, Suzuma K, Suzuma I, et al. Vitreous levels of angiopoietin 2 and vascular endothelial growth factor in patients with proliferative diabetic retinopathy. Am J Ophthalmol 2005:139:476-81.

4. Mitchell P, Bandello F, Schmidt-Erfurth U, et al. RESTORE study group. The RESTORE study: ranibizumab monotherapy or combined with laser versus laser monotherapy for diabetic macular edema. Ophthalmology 2011;118:615-25.

5. Arevalo JF, Sanchez JG, Lasave AF, et al. Iravitreal Bevacizumab (Avastin) for Diabetic Retinopathy: The 2010 GLADAOF Lecture. J Ophthalmol 2011:2011:584238.

6. Ferrara N. Vascular endothelial growth factor: basic science and clinical progress. Endocr Rev 2004;25:581-611.

7. Kowanetz M, Ferrara N. Vascular endothelial growth factor signalling pathways: therapeutic perspective. Clin Cancer Res 2006;12:5018-22.

8. Qaum T, Xu Q, Joussen AM, et al. VEGF-initiated blood-retinal barrier breakdown in early diabetes. Invest Ophthalmol Vis Sci 2001:42:2408-13.

9. Nguyen QD, Tatlipinar S, Shah SM, et al. Vascular endothelial growth factor is a critical stimulus for diabetic macular edema. Am J Ophthalmol 2006;142:961-9.
10. Deissler H, Deissler H, Lang $\mathrm{S}$, et al. VEGF-induced effects on proliferation, migration and tight junctions are restored by ranibizumab (Lucentis ${ }^{\circledR}$ ) in microvascular retinal endothelial cells. Br J Ophthalmol 2008;92:839-43.

11. Deissler $\mathbf{H}$, Deissler $H$, Lang GE. Inhibition of protein kinase $\mathrm{C}$ is not sufficient to prevent or reverse effects of VEGF 165 on tight junction protein claudin-1 and permeability in microvascular retinal endothelial cells. Invest Ophthalmol Vis Sci 2010;51:535-42.

12. Stewart EA, Samaranayake GJ, Browning AC, et al. Comparison of choroidal and retinal endothelial cells: characteristics and response to VEGF-isoforms and anti-VEGF treatment. Exp Eye Res 2011;93:761-6.

13. Spitzer MS, Wallenfels-Thilo B, Sierra A, et al. Antiproliferative and cytotoxic properties of bevacizumab on different ocular cells. Br J Ophthalmol 2006;90:1316-21.

14. Deissler H, Deissler H, Lang GE. Inhibition of VEGF is sufficient to completely restore barrier malfunction induced by growth factors in microvascular retinal endothelia cells. Br J Ophthalmol 2011;95:1151-6.

15. Klettner A, Kruse ML, Meyer T, et al. Different properties of VEGF-antagonists: bevacizumab but not Ranibizumab accumulates in RPE cells. Graefes Arch Clin Exp Ophthalmol 2009;247:1601-8

16. Klettner A, Möhle F, Roider J. Intracellular Bevacizumab reduces phagocytotic uptake in RPE cells. Graefes Arch Clin Exp Ophthalmol 2010;248:819-24.

17. Miura Y, Klettner A, Roider J. VEGF antagonists decrease barrier function of retinal pigment epithelium in vitro: possible participation of intracellular glutathione. Invest Ophthalmol Vis Sci 2010;51:4848-55.

18. Ferrara N, Damico L, Shams N, et al. Development of ranibizumab, an anti-vascular endothelial growth factor antigen binding fragment, as therapy for neovascular age-related macular degeneration. Retina 2006;26:859-70.

19. Presta LG, Chen $\mathrm{H}, \mathrm{O}^{\prime}$ Connor J et al. Humanization of an anti-vascular endothelia growth factor monoclonal antibody for the therapy of solid tumors and other disorders. Cancer Res 1997; 57:4593-9.

20. Deissler $\mathbf{H}$, Deissler $\mathrm{H}$, Lang GK, et al. Generation and characterization of iBREC: novel hTERT-immortalised bovine retinal endothelial cells. Int $\mathrm{J}$ Mol Med 2005; 16:65-70.

21. Peters S, Julien S, Heiduschka $P$, et al. Antipermeability and antiproliferative effects of standard and frozen bevacizumab on choroidal endothelial cells. Br J Ophthalmol 2007:91:827-31.

22. Kahook MY, Liu L, Ruzycki P, et al. High-molecular-weight aggregates in repackaged bevacizumab. Retina 2010;30:887-92.

23. Zhang A, Singh SK, Shirts MR, et al. Distinct aggregation mechanisms of monoclona antibody under thermal and freeze-thaw stresses revealed by hydrogen exchange. Pharm Res 2012;29:236-50.

24. Heiduschka $\mathbf{P}$, Fietz $\mathrm{H}$, Hofmeister $\mathrm{S}$, et al. Tübingen Bevacizumab Study Group. Penetration of bevacizumab through the retina after intravitreal injection in the monkey. Invest Ophthalmol Vis Sci 2007:48:2814-23. 